\title{
Atypical placement of the pylorus: a rare congenital abnormality
}

The most common congenital abnormality of the pylorus is hypertrophic pyloric stenosis, which occurs in about 3 in every 1000 live births and is an extremely rare disorder in adulthood [1,2]. Other congenital abnormalities are less frequently seen; most of them present in infancy or childhood and cause gastric outlet obstruction $[3,4]$. We present here the case of an older man who was found to have congenital displacement of the pylorus without any previous evidence of obstructive symptoms.

A 60-year-old man was admitted with a 1-day history of black-colored stool. After he had been given intravenous fluid resuscitation and was hemodynamically stable, he underwent an esophagogastroduodenoscopy (EGD). During the endoscopic examination, the pylorus was not detected at the antrum ( $\bullet$ Fig.1a). Instead, an opening was found at the site of the incisural notch on the lesser curvature ( $\bullet$ Fig. 1 b). Just beyond the atypically positioned pylorus, ulcers were detected on both the anterior and posterior walls of the duodenal bulb ( Fig. 1 c).

The patient had had no chronic illnesses or previous abdominal surgery. He denied any drug intake. A rapid urease test for Helicobacter pylori was positive. A barium contrast study ( $\bullet$ Fig.2) and magnetic resonance imaging (MRI) scan ( $\bullet$ Fig.3) subsequently confirmed the atypical position of the pylorus without any additional intra-abdominal malrotation abnormalities or dextrogastria.

Pyloric abnormalities can be congenital or may be acquired, for example peptic ulcer, caustic ingestion, or tumor. Most patients present with obstructive symptoms; however, some patients are asymptomatic. Our patient was asymptomatic until he developed bleeding ulcers. Although $H$. pylori colonization was demonstrated, it is not known whether atypical placement of the pylorus affects the development of bulbar ulcers. It is possible that because of the atypical placement, the pyloric sphincter might be constantly open. Continuous acid reflux from the stomach to the bulb could contribute to mucosal injury and ulcer development in the bulb. Consequently, this unique congenital abnormal-

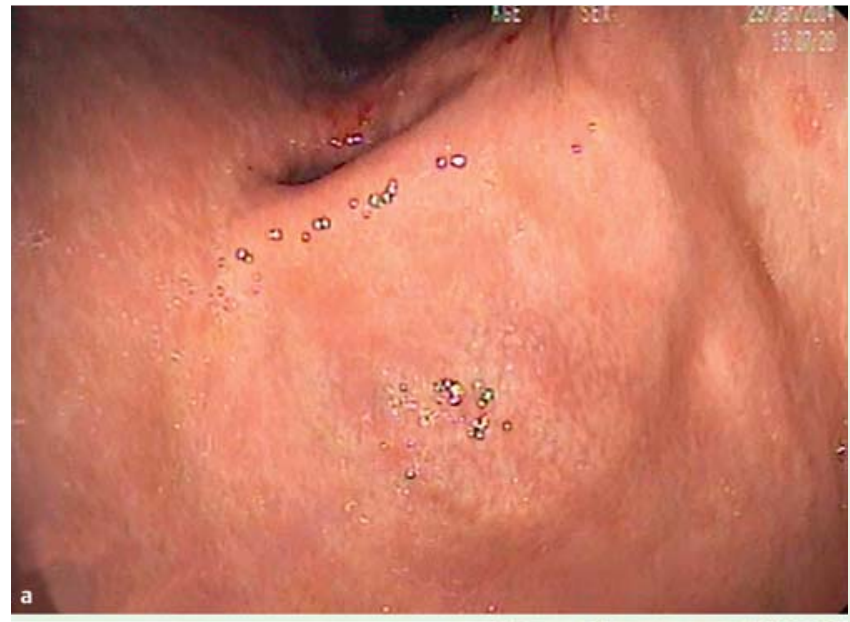

Fig. 1 Endoscopic views of: a the antrum; b the atypically placed pylorus at the incisura; c bulbar ulcers on both the anterior and posterior walls of the bulb.
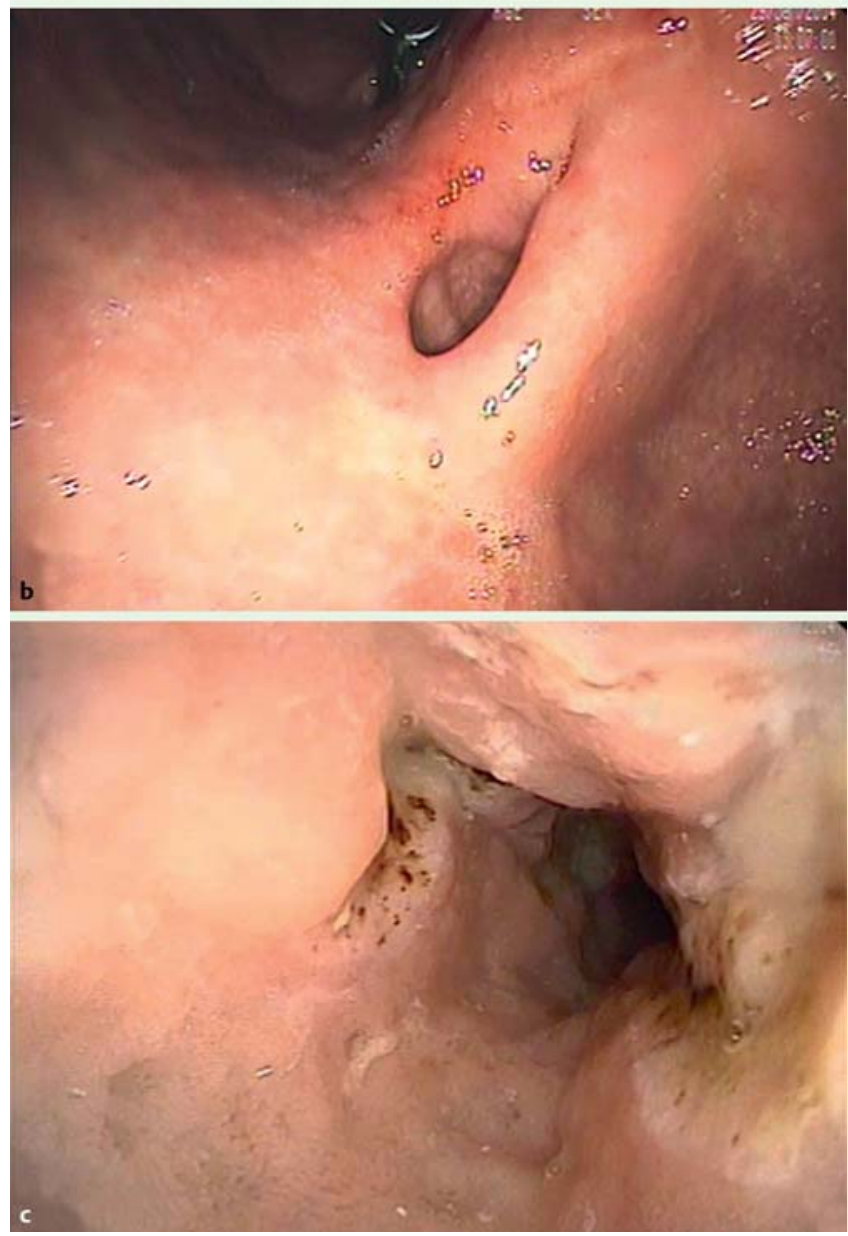

ity may have contributed to the patient's peptic ulcer disease.

Endoscopy_UCTN_Code_CCL_1AB_2AD_3AF

Competing interests: None 

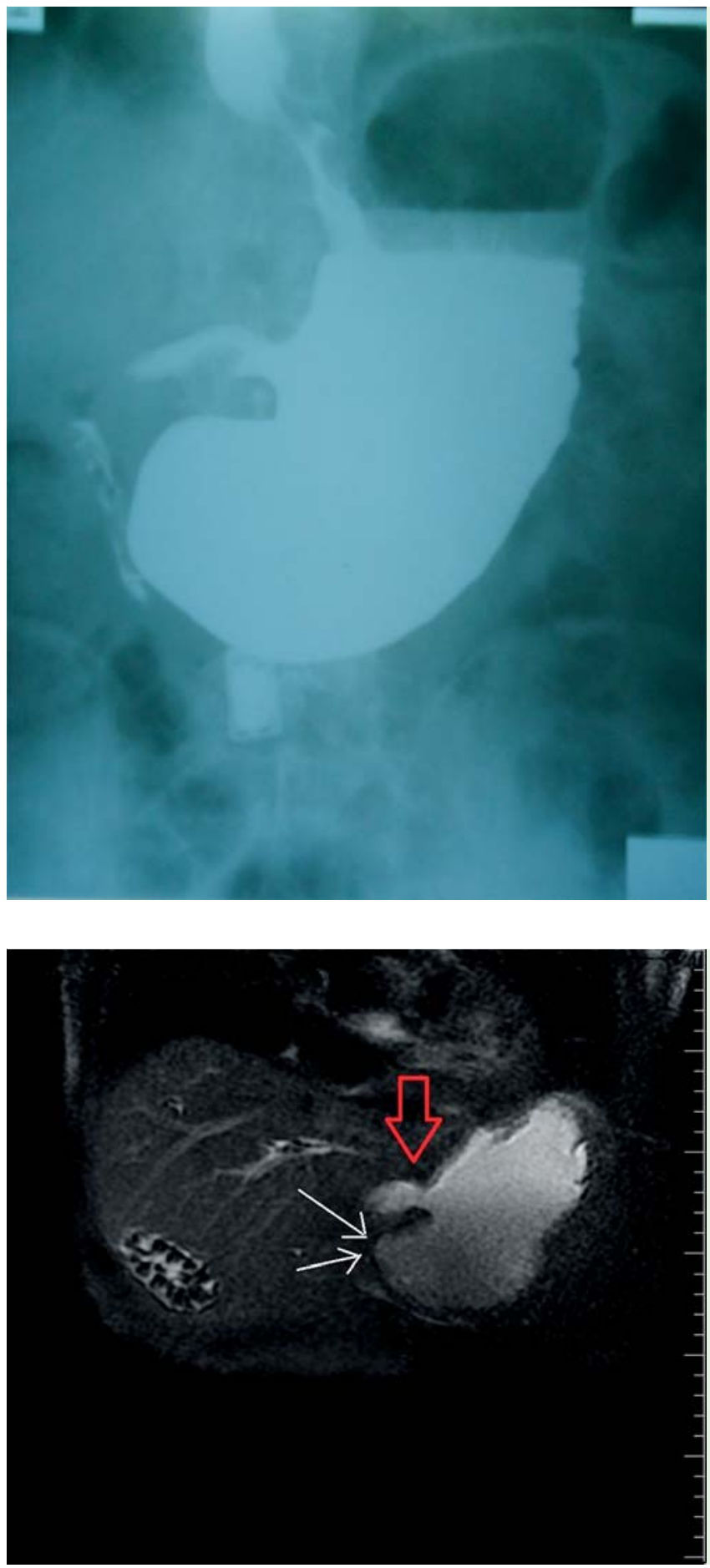

Fig.2 Barium study showing the atypical placement of the pylorus at the lesser curvature.

Fig. 3 Coronal

T1-weighted magnetic resonance imaging (MRI) scan showing the atypically placed pylorus and bulb (red arrow), with the expected position of the pylorus indicated by the white arrows.
Turan Calhan, Abdurrahman Sahin,

\section{Resul Kahraman, Aziz Batu}

Department of Gastroenterology, Sanliurfa Mehmet Akif Inan Education and Research Hospital, Sanliurfa, Turkey

\section{References}

1 Schechter R, Torfs CP, Bateson TF. The epidemiology of infantile hypertrophic pyloric stenosis. Paediatr Perinat Epidemiol 1997; 11: 407-427

2 Hellan M, Lee T, Lerner T. Diagnosis and therapy of primary hypertrophic pyloric stenosis in adults: case report and review of literature. J Gastrointest Surg 2006; 10: 265 269

3 Feng J, Gu W, Li M et al. Rare causes of gastric outlet obstruction in children. Pediatr Surg Int 2005; 21: 635-640

4 Otjen JP, Iyer RS, Phillips GS et al. Usual and unusual causes of pediatric gastric outlet obstruction. Pediatr Radiol 2012; 42: 728 737

\section{Bibliography}

DOI http://dx.doi.org

10.1055/s-0034-1377214

Endoscopy 2014; 46: E302-E303

(c) Georg Thieme Verlag KG

Stuttgart · New York

ISSN 0013-726X

\section{Corresponding author}

\section{Turan Calhan, MD}

Sanliurfa Mehmet Akif Inan Education

and Research Hospital

Esentepe Mah

Ertuğrul Cad

Sanliurfa

Turkey

Fax: +90-414-3186812

trncalhan@hotmail.com 